\title{
Study on the impact of the angular value of scoliosis, the number and lenght of the curves on physical capacity of affected girls
}

\author{
D Czaprowski ${ }^{1 *}$, T Kotwicki $^{2}$, R Biernat ${ }^{1}$, A Ronikier $^{3}$ \\ From 8th International Conference on Conservative Management of Spinal Deformities and SOSORT 2011 \\ Annual Meeting \\ Barcelona, Spain. 19-21 May 2011
}

\section{Purpose of the study}

To determine the influence of the scoliosis angle, the number and the length of the curves on physical capacity of affected girls.

\section{Background}

Physical capacity determines the organism's ability to make a physical effort, to tolerate dysfunctions of endogenous homeostasis caused by the physical effort and to quickly regain balance [1][2]. Idiopathic scoliosis (IS) is a systemic disease affecting function of the cardiopulmonary system and impairing patient's physical capacity $[3,5,6]$.

\section{Materials and methods}

Ninety-seven girls, aged 10 to18, seventy idiopathic scoliosis and 27 controls participated in the study. To determine the physical capacity, the indirect method comprising the PWC170 test was used and maximal oxygen uptake (VO2 $\max , 1 / \mathrm{min})$ was calculated $[3,5]$. Girls with moderate IS $\left(\right.$ Cobb $25^{\circ}-40^{\circ}$ ) and mild IS (Cobb up to $25^{\circ}$ ) were analyzed separately.

\section{Results}

The $\mathrm{VO}_{2}$ max value $(1 / \mathrm{min})$ and the PWC170 index were significantly lower in girls with moderate IS compared to control group. No difference was found between mild IS and controls. No influence of the number of curves and the length of scoliosis on $\mathrm{VO}_{2} \max (1 / \mathrm{min} ; \mathrm{ml} / \mathrm{kg} / \mathrm{min})$ and the absolute capacity value (W) was found. A significantly lower value of the PWC $170(\mathrm{~W} / \mathrm{kg}$ ) index was observed in girls with double scoliosis and girls having the curve over 9 vertebrae.

${ }^{1}$ Faculty of Physiotherapy, Józef Rusiecki University College in Olsztyn, Poland Full list of author information is available at the end of the article

\section{Conclusions}

Girls with moderate IS presented lower $\mathrm{VO}_{2}$ max compared to controls. Physical capacity of mild IS was not significantly different from controls. Girls with double scoliosis and girls having the curve over 9 vertebrae had a significantly lower value of the PWC $170(\mathrm{~W} / \mathrm{kg})$ index, moreover no significant effects were found for $\mathrm{VO}_{2} \max$ and PWC $170(\mathrm{~W})$.

\section{Author details}

${ }^{1}$ Faculty of Physiotherapy, Józef Rusiecki University College in Olsztyn, Poland. ${ }^{2}$ University of Medical Sciences, Poznań, Poland. ${ }^{3}$ Faculty of Rehabilitation, Academy of Physical Education, Warsaw, Poland.

Published: 27 January 2012

References

1. Astrand PO, Rodahl K: Textbook of work physiology. New York: Mc Graw Hill; 1986.

2. Cleland V, Wyder T, Blizzard L, Venn A: The provision of compulsory school physical activity: Associations with physical activity, fitness and overweight in childhood and twenty years later. Int J Behav Nutr Phys Act 2008, 5:14, doi: 10.1186/1479-5868-5-14.

3. Coast JR, Cline CC: The effect of chest wall restriction on exercise capacity. Respirology 2004, 9:197-203.

4. Durmała J, Tomalak W, Kotwicki T: Function of the respiratory system in patients with idiopathic scoliosis: reasons for impairment and methods of evaluation. Stud Health Technol Inform 2008, 135:237-245.

5. Hawkins MN, Raven PB, Snell PG, Stray-Gundersen J, Levine BD: Maximal oxygen uptake as a parametric measure of cardiorespiratory capacity. Med Sci Sports Exerc 2007, 39:103-107.

6. Koumbourlis AC: Scoliosis and the respiratory system. Paediatr Respir Rev 2006, 7:152-160.

\section{doi:10.1186/1748-7161-7-S1-061}

Cite this article as: Czaprowski et al: Study on the impact of the angular value of scoliosis, the number and lenght of the curves on physical capacity of affected girls. Scoliosis 2012 7(Suppl 1):O61. 